\title{
HUMIDIFICATION OF THE AIR PASSAGES
}

BY

\author{
V. E. NEGUS \\ London
}

(RECEIVED FOR PUBLICATION MARCH 6, 1952

The origin of the animal kingdom was in the sea and the need of a watery medium is still to be seen in mammalian organization. Man, like all others, cannot survive without a supply of water, not only for the tissues but also as a covering for their mucosal surfaces.

\section{REASONS FOR HUMIDIFICATION}

The reasons for moistening of the mucous membranes are several. Ciliary action is dependent on a supply of mucus, of the right viscosity and in correct amount; in this blanket of mucus are carried lysozymes, described by Fleming (1928), of considerable bacteriostatic and bactericidal importance.

The alveoli of the lung must be kept moist, for otherwise respiratory exchanges cannot be carried on; the origin of this necessity is to be found in fish which left the sea to pass part of their lives on land, as for example the climbing perch.

The olfactory area must have a supply of moisture to dissolve the particles which convey the sensation of smell; the vocal folds must be lubricated with mucus, for otherwise they will not vibrate.

The pharynx must not be dry if deglutition is to be efficient; here saliva helps, but not continuously.

Transudation helps to some degree in the respiratory tract, but not by itself, since evaporation would be excessive if the inspired air were charged with insufficient moisture; there would be consequent damage to the mucosa and deleterious effects, to be considered later.

\section{Supply OF MOISTURE From THE MucosA}

The moistening of the surfaces lining the respiratory tract depends to a considerable extent, but not entirely, on the passage of water from the tissues. This takes two forms, secretion from racemose mucous glands and gotlet cells, and transudation through the cell walls. The combination of the two produces what is generally known as mucus, a secretion of a viscosity varying with the amount of protein present. The permeability of the cell walls is subject to great alterations, as seen in allergic states such as hay fever and in bronchorrhoea ${ }^{\infty}$ Capillaries are said to be 3,000 times more pers meable than cell membranes (Marriott, 1950) $\vec{c}$ Many factors, such as the concentration of various essential ions, and also the reaction or $p \mathrm{H}$ are of importance in altering transudation, but the subjecto cannot be pursued here.

Squamous epithelium, as in the pharynx, is not so well designed for humidification as such mucosa surfaces as those of the nose, sinuses, trachea and bronchi; the number of goblet cells and race mose glands varies considerably, being mos numerous in the nose. The vascularity also is irregular, blood supply being free in the nose and poor in the sinuses. The nose is, in fact, eminentlys designed to give up moisture and is the main sources of supply. Nearly a litre can be supplied in 24 hours; practically all this water is lost on expira tion.

The advantage of a specialized air conditioningo organ, such as the nose, is its adaptability to varying? conditions, under control of the sympathetic system 0

If the nose is inefficient for purposes of humidification, as in atrophic rhinitis, or obstructed by deviations of the septum or by polyposis, then the respiratory passages suffer temporarily or: permanently; similarly if air enters the tracheaN directly through a stoma.

\section{SUPPLy OF MOISTURE FROM THE ATMOSPHERE}

Terrestrial life started by migration from theo sea and therefore the earliest habitat was humid; even now residence by the ocean is looked on as ${ }^{+}$ favourable for many complaints.

A considerable part of the moisture required for the air passages is derived from the atmosphere, $\frac{?}{8}$ and therefore consideration must be given to the physical factors concerned; at the risk of discussing a subject which may appear obvious and elementary, it seems desirable to consider the variations of humidity. 


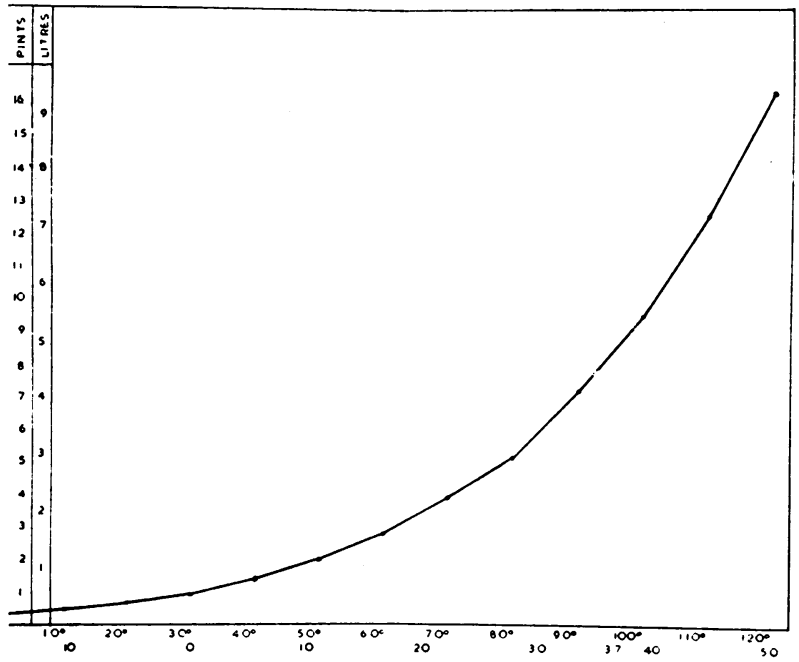

Fig. 1.-Graph of absolute humidity: carrying power of $4,000 \mathrm{cu}$. ft. air (a room $20 \mathrm{ft}$. $\times 20 \mathrm{ft}$. $\times 10 \mathrm{ft}$ ), if saturated (100\% humidity) at the given temperature.

\section{Absolute Humidity}

By absolute humidity is meant the carrying power of the atmosphere for water. This carrying power varies directly with the temperature; it also varies with changes of barometric pressure.

Fig. 1 shows the maximum amount of water in pounds, pints, or litres that can be held in 4,000 cubic feet of air, equal to the capacity of a room $20 \mathrm{ft} . \times 20 \mathrm{ft}$. $\times 10 \mathrm{ft}$.
At freezing point $\left(32^{\circ} \mathrm{F}\right.$.) the amount is just over $1 \mathrm{lb}$. weight, but at $122^{\circ} \mathrm{F}$. it is more than $20 \mathrm{lb}$.

If the amount of water exceeds the maximum that can be carried the excess is precipitated as droplets; dew point is then said to be reached.

Since cold air contains very little moisture it follows that, on high mountains and even more so in the stratosphere, the air is intensely dry; at 35 or $40,000 \mathrm{ft}$., in intense cold, the amount of water in $4,000 \mathrm{cu}$. $\mathrm{ft}$. of air may be as little as $0.00008 \mathrm{lb}$. (Goldie, personal communication).

\section{Relative Humidity}

The maximum amount of water is not present in the air except at dew point, which means $100 \%$ degree of saturation. The relation of the actual quantity to the possible maximum is known as relative humidity, representing the degree of approach to saturation (Fig. 2). Thus $2.6 \mathrm{lb}$. of water, being over dew point at $52^{\circ} \mathrm{F}$., would produce droplets or a mist; but in the hot, northern Sahara, at a temperature of $122^{\circ} \mathrm{F}$., it would leave the air extremely dry, the relative humidity being as low as $10 \%$ (Goldie, personal communication).

Change of altitude alters the relation, as seen in the formation of clouds, when clear air from the earth's surface rises and reaches a cold, attenuated atmosphere.

Fig. 2 also indicates the changes that occur when air from the outside is taken into a room and

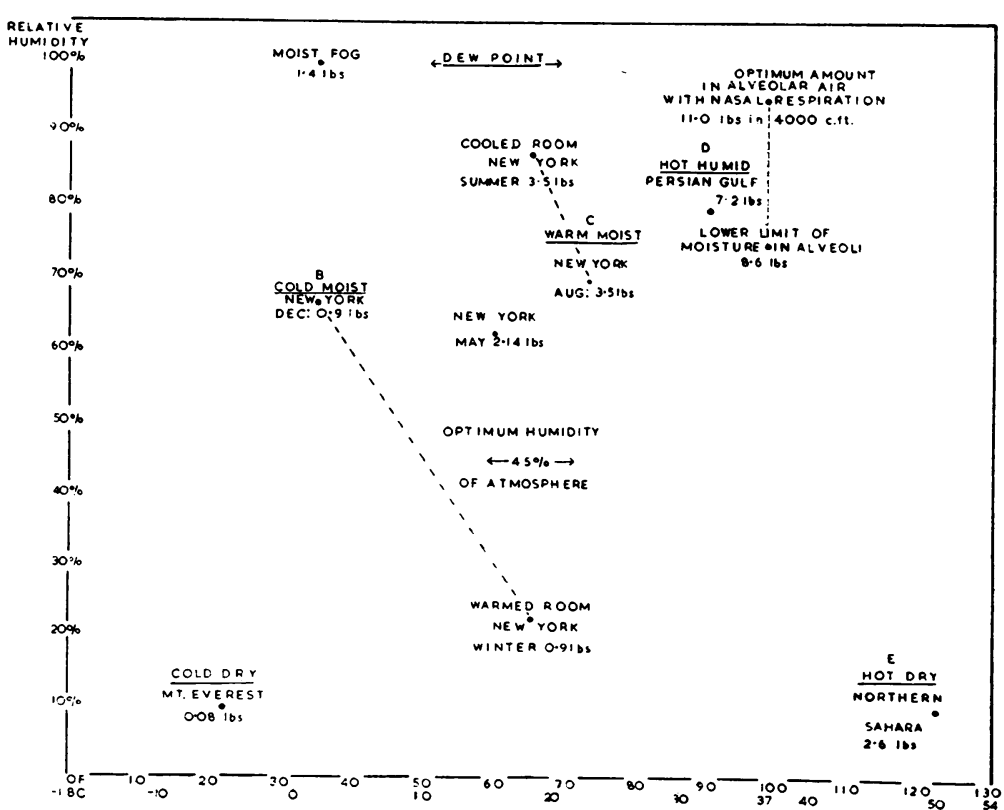

FIG. 2.-Relation of absolute and relative humidity under various climatic conditions The figures show the water content in $1 \mathrm{~b}$. in a room $20 \mathrm{ft}$. $\times 20 \mathrm{ft} . \times 10 \mathrm{ft} ., 4,000 \mathrm{cu} . \mathrm{ft}$. warmed, with a drop in relative humidity to an unpleasantly low degree; the opposite occurs when warm moist air is cooled (Proetz, 1941). Absolute humidity varies directly with and relative humidity inversely to the temperature.

Humidity also varies with the surroundings; thus the higher reaches of Mount Everest are intensely dry, and so is the Sahara, while the hot Persian Gulf or the cold countryside of England may be excessively humid.

\section{REQUIREMENTS OF THE HUMAN BODY}

Unlike some animals such as birds and dogs, the human being regulates the body temperature by sweating. Therefore the hot, dry 
Sahara or the desert of Irak may be tolerable, while the steaming Persian Gulf is almost or entirely unbearable. In any question of artificial humidification this physiological process must be kept in mind.

The optimum relative hum dity is put at $45 \%$ by Proetz (1941), but it may be 50 or even $55 \%$ with advantage, according to some authorities.

The bronchi and alveoli require a relative humidity of $95 \%$ (Proetz, 1941); a lower degree would lead to excessive evaporation from the mucosal surfaces, and one nearer $100 \%$ would have the danger of precipitation of droplets at dew point, if the temperature of the air in the bronchi dropped for any reason.

Hilding (1949) has described the subdivision of the tracheo-bronchial tree, estimating that there are over 25,000 terminal bronchioles; the calibre is naturally minute and easily plugged by secretion; the size of droplets will usually cause them to be held up before they reach the terminations of the air passages.

\section{SOURCE OF MOISTURE}

The nose gives up the greater amount required, being designed for this purpose; after tracheostomy or laryngectomy trouble may arise, but with eventual adaptation.

Air passing through the nose is warmed by the heat given off from the controlled blood supply, and is said to be brought nearly up to body temperature (MacDonald, 1889). Without going into the many possibilities, I put forward what appears to me to be the correct reason for this warming; no satisfactory previous explanation appears to have been suggested. Cold air cannot carry much moisture; therefore, if the air reaching the larynx is to be almost saturated with moisture it must first be warmed to bring its potential absolute humidity to a high level. Having warmed the inspired current, the nose can then charge it with the required amount of water.

Even if cold air entered the nose with a relative humidity of 100 , it would, in 24 hours. by the time it reached the alveoli, have been warmed to such a degree that its relative humidity would be very low and insufficient.

Of the water required to bring the humidity of $\frac{\vec{\sigma}}{\vec{D}}$ air reaching the bronchi up to $95 \%$, a varying $\stackrel{\varrho}{\circ}$ quantity is derived from the atmosphere, according $\omega$ to the geographical situation, the temperature, $\vec{O}$ the barometric pressure, and the available supply; $\vec{\overrightarrow{ }}$ the remainder comes from the mucosa and mainly $\vec{\omega}$ from the nose.

Fig. 3 shows the quantity taken up in 24 hours, during which period $500 \mathrm{cu}$. ft. of air are respired. iv Various conditions are illustrated in this table, $\overrightarrow{\vec{A}}$ showing the alterations of relative humidity when $\infty$ the atmospheric air is warmed in the nose; in the $\frac{}{5}$ vertical series of parallelograms the amount derived from the air is shown in black and that from the $\subseteq$ mucosa in white, the total required being $19 \mathrm{oz}$.

\section{Means of Artificial Humidification}

The comfortable relative humidity of the air is 45 to $50 \%$, but under certain conditions a higher level is desirable. Thus, after tracheostomy or laryngectomy the tracheo-bronchial tree takes some time for adaptation, and at first is unable to $\stackrel{\unrhd}{\circledR}$ supply sufficient moisture. Potassium iodide in small $\overrightarrow{\overrightarrow{0}}$ doses gives some help, but pilocarpine, although $\exists$ efficient, has unpleasant effects. The addition of

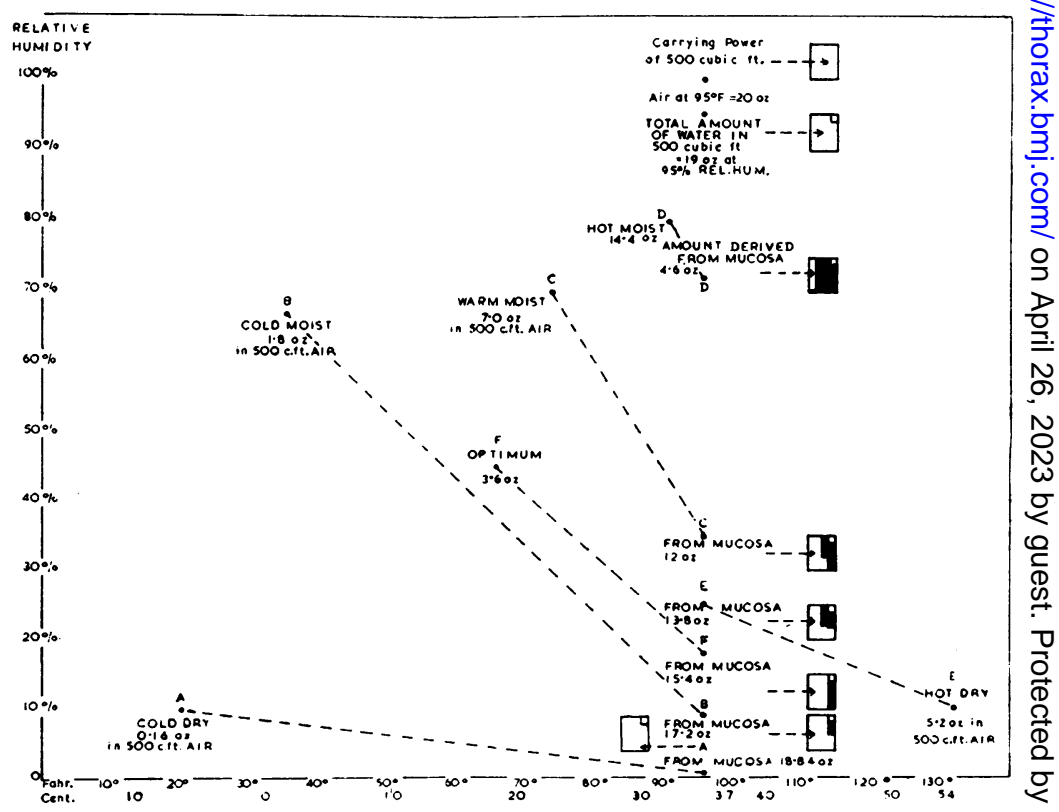

FIG. 3.-Graph to indicate the amount of moisture supplied by the atmosphere under various conditions, the external air being brought to body temperature, with consequent alterations in relative humidity. The volume of air is $500 \mathrm{cu}$. ft., which is the tidal air respired 
moisture to the air is desirable, and in one of the wards of the oto-laryngological hospital of Helsinki University the relative humidity is kept at $70 \%$ (Meurman, personal communication), with a room temperature of almost $67^{\circ} \mathrm{F}$. $\left(20^{\circ} \mathrm{C}\right.$. $)$.

In acute tracheo-bronchitis secretions may be over-viscid and obstructive and here again a level of $70 \%$ is to be aimed at, or even $90 \%$ (Mathieu, West, Lehman, and Mathieu, 1951).

Hot steam is undesirable, except by inhalation from a jug, since there is precipitation of droplets in the colder air surrounding the patient; to maintain a relative humidity of $50 \%$ in a tent, the temperature would rise to $90^{\circ} \mathrm{F}$., with moisture condensing and dripping (Mathieu and others, 1951).

Cold moisture is desirable and may be delivered into a ward by an external humidifying plant (Meurman), by means of a portable electric humidifier (Holinger, personal communication), or from a nebulizer actuated by an oxygen cylinder (Mathieu and others, 1951).

To reduce the surface tension of water and thus to facilitate its vaporization, various wetting agents may be employed; sodium lauryl sulphate in $0.1 \%$ solution is recommended and is said, not only to be harmless to the skin and mucous membranes in this strength, but also to be antibiotic (Mathieu and others, 1951).

If additional oxygen is required it may be supplied directly to the tent, in addition to that passing through the nebulizer, bringing the percentage up to 40 .

For usual purposes the humidity will not be raised above $70 \%$.
After laryngectomy a shield over the tracheostome, covered with five layers of gauze, acts as an airconditioning plant by conserving the warmth and moisture of expired air.

\section{Derangements Due to EXCESSIVE OR INSUFFICIENT MOISTURE}

Insufficiently moistened air reaches the bronchioles and alveoli in cases of atrophic rhinitis; after the excessive use of vasoconstrictors; after tracheostomy or laryngectomy; in dry regions such as western Australia, the Sahara Desert, and the upper reaches of high mountains; similarly in a hot operating theatre if not properly air conditioned, and in patients after operations if too much atropine has been given.

Excessive moisture plugs the smaller bronchi in cases of bronchitis, bronchiectasis, and bronchial and lung abscess, and must be removed; but often removal can be effected by the ciliary streams if excessive viscosity is relieved by the addition of water vapour.

Although considered but briefly, it is obvious how great an importance attaches to humidification.

\section{REFERENCES}

Fleming, A. (1928). J. Laryng., 43, 385.

Goldie, A. H. R. (Deputy Director, Meteorological Office, Air Ministry.) Personal communication.

Hilding, A. C. (1949). Acta oto-laryng., Stockh., 37, 138.

Holinger, P. (Chicago.) Personal communication.

MacDonald, G. (1889). Of the Respiratory Functions of the Nose. acDonald,
London.

Marriott, H. L. (1950). Ann. roy. Coll. Surg. Engl., 7, 339.

Mathieu, P. L., West, E., Lehman, S., and Mathieu, B. (1951) Ann. Otol., St. Louis, 60, 668.

Meurman, Y. R. J. Ö. (Helsinki.) Personal communication.

Proetz, A. W. (1941). Essays on the Applied Physiology of the Nose. St. Louis. 